Case Report

\title{
Severe Hyperammonemia in Late-Onset Ornithine Transcarbamylase Deficiency Triggered by Steroid Administration
}

\author{
Jordi Gascon-Bayarri, ${ }^{1}$ Jaume Campdelacreu, ${ }^{1}$ Jordi Estela, ${ }^{2}$ and Ramon Reñé ${ }^{1}$ \\ ${ }^{1}$ Unitat de Diagnòstic i Tractament de les Demències, Neurology Service, Hospital Universitari de Bellvitge, Feixa Llarga s/n, \\ 08907 L'Hospitalet de Llobregat, Spain \\ ${ }^{2}$ Neurology Service, Hospital Universitari Parc Taulí, Parc del Taulí 1, 08208 Sabadell, Spain \\ Correspondence should be addressed to Jaume Campdelacreu; 33357jcf@comb.cat
}

Received 24 November 2014; Accepted 29 March 2015

Academic Editor: Majaz Moonis

Copyright ( $\odot 2015$ Jordi Gascon-Bayarri et al. This is an open access article distributed under the Creative Commons Attribution License, which permits unrestricted use, distribution, and reproduction in any medium, provided the original work is properly cited.

Ornithine transcarbamylase deficiency (OTCD) is a rare X-linked disorder of urea synthesis leading to hyperammonemia. Several late-onset cases have been reported. Undiagnosed and untreated patients are at the risk of death or suffering from irreversible sequelae. We describe a 56-year-old patient who presented with acute encephalopathy after steroid treatment. Hyperammonemia due to OTCD was diagnosed and a mutation was found. This allowed us to diagnose two other family members with unexplained encephalopathy who are now asymptomatic on a low-protein diet. OTCD should be considered in any patient with hyperammonemic encephalopathy and immediate treatment should be given to avoid a fatal outcome. We emphasize the need to examine other family members if the diagnosis is confirmed, in order to prevent further life-threatening episodes of encephalopathy or neonatal coma of newborn.

\section{Introduction}

Ornithine transcarbamylase deficiency (OTCD) is a rare Xlinked disorder of urea synthesis leading to hyperammonemia [1] that usually presents in newborn. An increasing number of late-onset cases have been reported in adults, most of them females $[2,3]$ with symptom onset coinciding with a precipitating factor [4]. However, in some cases the trigger cannot be identified [5]. Without treatment patients may die or suffer from irreversible cognitive sequelae [1]. It is therefore crucial to identify these late-onset patients and to test the rest of the family if a mutation is found.

\section{Case Presentation}

A previously healthy 56-year-old Spanish man was admitted due to acute disorientation and agitation. He had suffered a common cold 3 weeks before. Four days prior to admission he had received a steroid injection to treat his knee arthritis. He had a decreased level of consciousness (Glasgow Coma
Scale 9) but a normal physical examination. He required sedation and orothracheal intubation. Blood tests revealed mild leukocytosis $\left(14,46 \times 10^{9} / \mathrm{L}\right)$ and high ammonium levels $(320 \mu \mathrm{g} / \mathrm{dL})$, with normal $\mathrm{pH}$, liver, and renal function, negative serologies and antibodies (HSV, HIV, autoantibodies, and antineuronal antibodies), and normal CSF (biochemistry, cell count, HSV PCR, culture). Brain CT and MR were normal. EEG showed a severe encephalopathy with acute bifrontal activity. A mycoplasma serology was positive and parainfectious encephalitis was suspected because of the previous cold. A urea cycle disorder triggered by drugs was also considered and amino acids were measured in blood and urine, showing no relevant abnormalities. Urine orotic acid was not measured. The clinical picture and the ammonium levels resolved after hemodialysis.

Two months later he underwent a laser cordotomy and required steroid treatment because of glottic edema. Four days later he developed progressive encephalopathy and required orothracheal intubation again. Blood tests revealed hyperammonemia and leukocytosis; the rest of the blood 


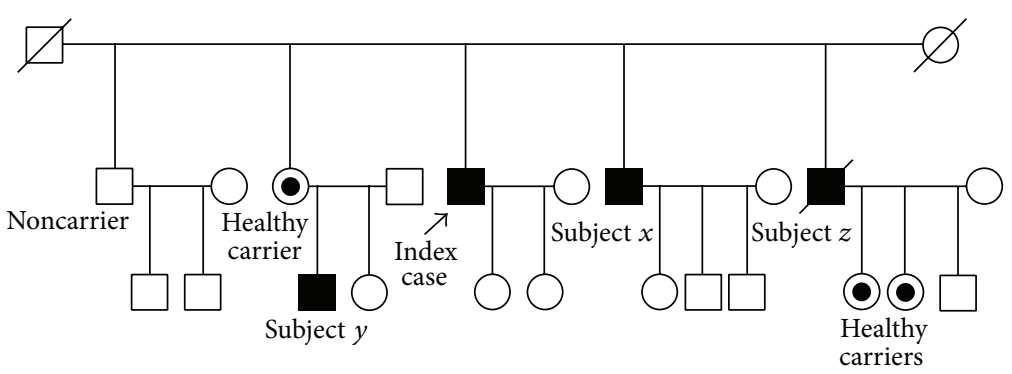

FIGURE 1: Family tree. Subjects $x$ and $y$ are affected carriers. Subject $z$ has two carrier daughters and is suspected to have been an affected carrier.

and CSF tests were again normal. OTCD was suspected and DNA analysis revealed a c.622G $>$ A (p.A208T) mutation. The patient improved after hemodialysis and has remained asymptomatic.

Other family members were studied (Figure 1). Two of them had been suffering from episodes of encephalopathy and could be finally diagnosed. Subject $x$ (brother) is a 55year-old male, who had complained of excessive somnolence after meals for 3 years previously, which resolved after starting a low-protein diet; he was recently admitted because of hyperammonemic encephalopathy triggered by infection and steroid treatment, which resolved after hemodialysis. He had a normal basal amino acid profile and urine orotic acid. The diagnosis was genetically confirmed. Subject $y$ (nephew) had suffered several episodes of hyperammonemic encephalopathy from the age of 13; the first episode had been attributed to metoclopramide, the following one to juvenile epilepsy, and the last ones to azathioprine treatment for Crohn's disease. Since OTCD was confirmed two years ago, he has followed a low-protein diet. He has normal ammonia and amino acid levels and has not suffered any other episodes. Subject $z$ (brother) had died with encephalopathy and brain edema of an unknown cause. He was a donor and his liver was rejected for transplantation because of its pathological macroscopic appearance. His two daughters are mutation carriers, but not his wife, so the patient must have been affected.

\section{Discussion}

Patients with late-onset OTCD are frequently misdiagnosed as encephalitis, poisoning, psychotic illness, or epilepsy. A personal or family history of similar episodes and precipitating factors should be investigated [4]. Hyperammonemia can be triggered by high protein intake, increased protein catabolism due to infection, trauma, physical exercise or steroids, hepatic toxicity from chemotherapy and other medications, pancreatitis, or postpartum [5-8]. There are at least five reports of OTCD adults who developed acute hyperammonemic coma following steroid administration [3, 6, 9-11]. Glucocorticoids are known to have a general catabolic effect by primarily enhancing protein turnover [12].

Ammonia should be measured in patients of any age presenting an unexplained encephalopathy and a urea cycle defect should be suspected if the patient has a normal liver function. Elevated glutamine and alanine plasma levels, decreased citrulline, and presence of orotic acid in the urine are usually found in OTCD [13], but these can be within normal range in the compensated state, as was the case of subject $x$. These tests should be performed in the acute phase, and if this is not possible, samples should be frozen for further testing. Regardless of the results, if the suspicion of OTCD is high, a genetic analysis should be performed.

Mutation analysis is the method of choice for the definitive diagnosis. In the majority of patients the mutation appears de novo (mother not carrier). In almost $20 \%$ of OTCD patients the mutation is not identified $[14,15]$; OTC enzyme activity assay in liver or intestinal mucosa can help in such cases. The measure of urinary orotidine excretion in women after the administration of a single dose of allopurinol (allopurinol challenge test) is also a simple and reliable method of assigning carrier status to women suspected of carrying a mutation [16].

A review in 2006 identified 341 mutations of the OTC gene [15] and new ones are being discovered (http://www .biobase-international.com/product/hgmd). The mutation found in our family has been already reported in other families $[17,18]$, with a variable age of onset and presentation, from asymptomatic to fatal coma.

Hemodialysis is the treatment of choice for rapid reduction of ammonia levels in adults and should be started quickly, even before confirming the diagnosis, in order to prevent intracranial hypertension and cerebral edema. Other measures include intravenous hydration with glucose and lipids, ammonia scavengers, $L$-arginine, and cessation of protein intake $[6,19]$. Long-term management is based on a low-protein diet. Liver transplantation may be considered in selected patients [14].

The possibility of an OTCD should be considered in any patient with hyperammonemic encephalopathy and treated rapidly to avoid fatal coma or long-term cognitive sequelae. We emphasize the importance of measuring ammonia and considering the diagnosis of urea cycle disorders in any patient with encephalopathy. The other family members need to be examined if the diagnosis is confirmed because it is a treatable condition and therefore further life-threatening episodes of encephalopathy or neonatal coma of the newborn can be appropriately prevented and rapidly treated. 


\section{Conflict of Interests}

The authors declare that there is no conflict of interests regarding the publication of this paper.

\section{References}

[1] O. M. Panlaqui, K. Tran, A. Johns, J. McGill, and H. White, "Acute hyperammonemic encephalopathy in adult onset ornithine transcarbamylase deficiency," Intensive Care Medicine, vol. 34, no. 10, pp. 1922-1924, 2008.

[2] C. M. Rüegger, M. Lindner, D. Ballhausen et al., "Crosssectional observational study of 208 patients with non-classical urea cycle disorders," Journal of Inherited Metabolic Disease, vol. 37, no. 1, pp. 21-30, 2014.

[3] C. Cavicchi, M. Donati, R. Parini et al., "Sudden unexpected fatal encephalopathy in adults with OTC gene mutations-Clues for early diagnosis and timely treatment," Orphanet Journal of Rare Diseases, vol. 9, article 105, 2014.

[4] S. Heringlake, K. Böker, and M. Manns, "Fatal clinical course of ornithine transcarbamylase deficiency in an adult heterozygous female patient," Digestion, vol. 58, no. 1, pp. 83-86, 1997.

[5] D. L. Roberts, D. A. Galbreath, B. M. Patel, T. J. Ingall, A. Khatib, and D. J. Johnson, "Hyperammonemic coma in an adult due to ornithine transcarbamylase deficiency," Case Reports in Critical Care, vol. 2013, Article ID 493216, 4 pages, 2013.

[6] S. Lipskind, S. Loanzon, E. Simi, and D. W. Ouyang, "Hyperammonemic coma in an ornithine transcarbamylase mutation carrier following antepartum corticosteroids," Journal of Perinatology, vol. 31, no. 10, pp. 682-684, 2011.

[7] M. C. Machado, G. M. Fonseca, and J. Jukemura, "Late-onset ornithine carbamoyltransferase deficiency accompanying acute pancreatitis and hyperammonemia," Case Reports in Medicine, vol. 2013, Article ID 903546, 3 pages, 2013.

[8] N. F. Blair, P. D. Cremer, and M. C. Tchan, "Urea cycle disorders: a life-threatening yet treatable cause of metabolic encephalopathy in adults," Practical Neurology, vol. 15, no. 1, pp. 45-48, 2015.

[9] M. L. Summar, F. Barr, S. Dawling et al., "Unmasked adult-onset urea cycle disorders in the critical care setting," Critical Care Clinics, vol. 21, no. 4, pp. S1-S8, 2005.

[10] M. Atiq, A. F. Holt, K. Safdar et al., "Adult onset urea cycle disorder in a patient with presumed hepatic encephalopathy," Journal of Clinical Gastroenterology, vol. 42, no. 2, pp. 213-214, 2008.

[11] R. J. Hawley, "Hyperammonia possibly due to corticosteroids," Archives of Neurology, vol. 57, no. 7, pp. 1085-1086, 2000.

[12] E. Löfberg, A. Gutierrez, J. Wernerman et al., "Effects of high doses of glucocorticoids on free amino acids, ribosomes and protein turnover in human muscle," European Journal of Clinical Investigation, vol. 32, no. 5, pp. 345-353, 2002.

[13] D. E. Choi, K. W. Lee, Y. T. Shin, and K. R. Na, "Hyperammonemia in a patient with late-onset ornithine carbamoyltransferase deficiency," Journal of Korean Medical Science, vol. 27, no. 5, pp. 556-559, 2012.

[14] J. Häberle, N. Boddaert, A. Burlina et al., "Suggested guidelines for the diagnosis and management of urea cycle disorders," Orphanet Journal of Rare Diseases, vol. 7, no. 1, article 32, 2012.

[15] S. Yamaguchi, L. L. Brailey, H. Morizono, A. E. Bale, and M. Tuchman, "Mutations and polymorphisms in the human ornithine transcarbamylase (OTC) gene," Human Mutation, vol. 27, no. 7, pp. 626-632, 2006.
[16] E. R. Hauser, J. E. Finkelstein, D. Valle, and S. W. Brusilow, "Allopurinol-induced orotidinuria: a test for mutations at the ornithine carbamoyltransferase locus in women," The New England Journal of Medicine, vol. 322, no. 23, pp. 1641-1645, 1990.

[17] J. Lien, W. L. Nyhan, and B. A. Barshop, "Fatal initial adult-onset presentation of urea cycle defect," Archives of Neurology, vol. 64, no. 12, pp. 1777-1779, 2007.

[18] O. P. Van Diggelen, J. Zaremba, W. He et al., "Asymptomatic and late-onset ornithine transcarbamylase (OTC) deficiency in males of a five-generation family, caused by an A208T mutation," Clinical Genetics, vol. 50, no. 5, pp. 310-316, 1996.

[19] O. D. Klein, D. R. Kostiner, K. Weisiger et al., "Acute fatal presentation of ornithine transcarbamylase deficiency in a previously healthy male," Hepatology International, vol. 2, no. 3, pp. 390-394, 2008. 


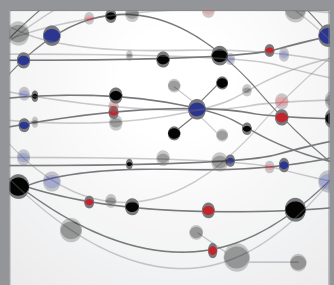

The Scientific World Journal
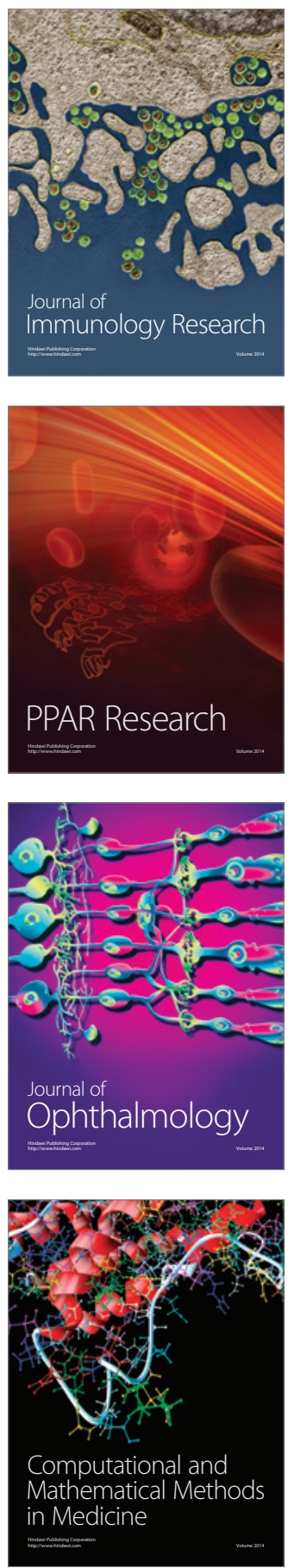

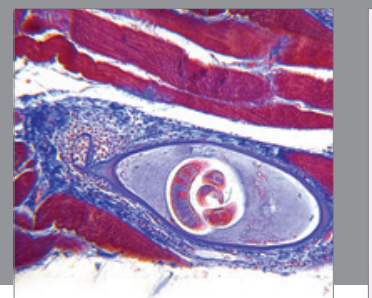

Gastroenterology

Research and Practice
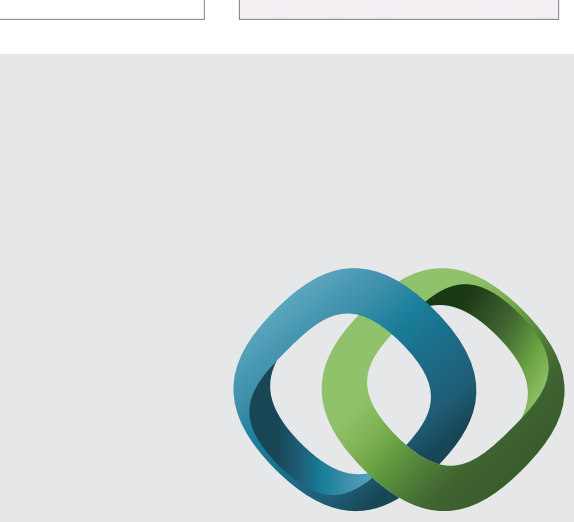

\section{Hindawi}

Submit your manuscripts at

http://www.hindawi.com
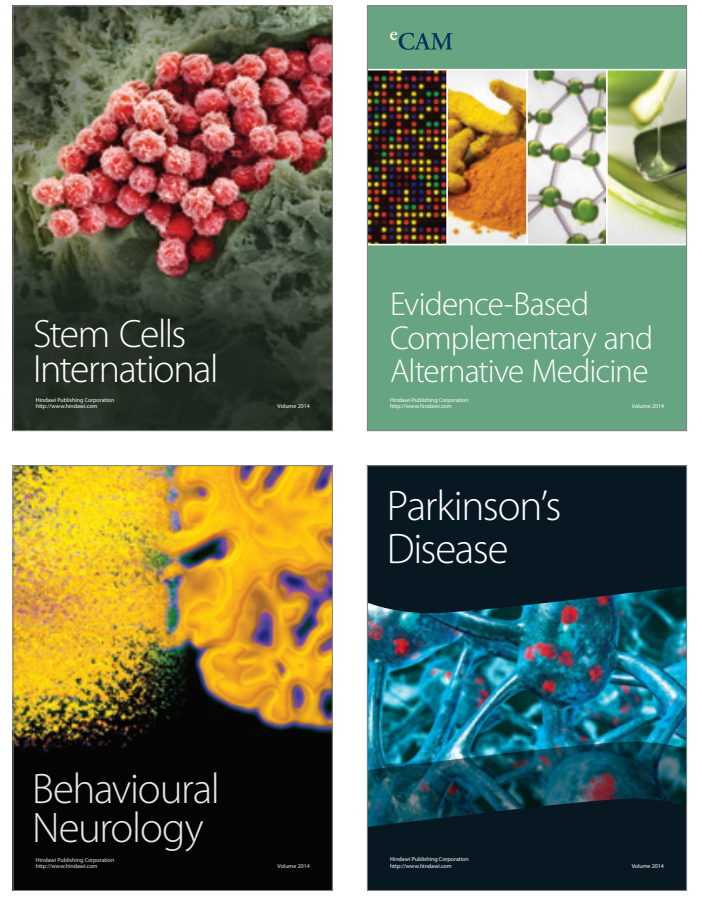
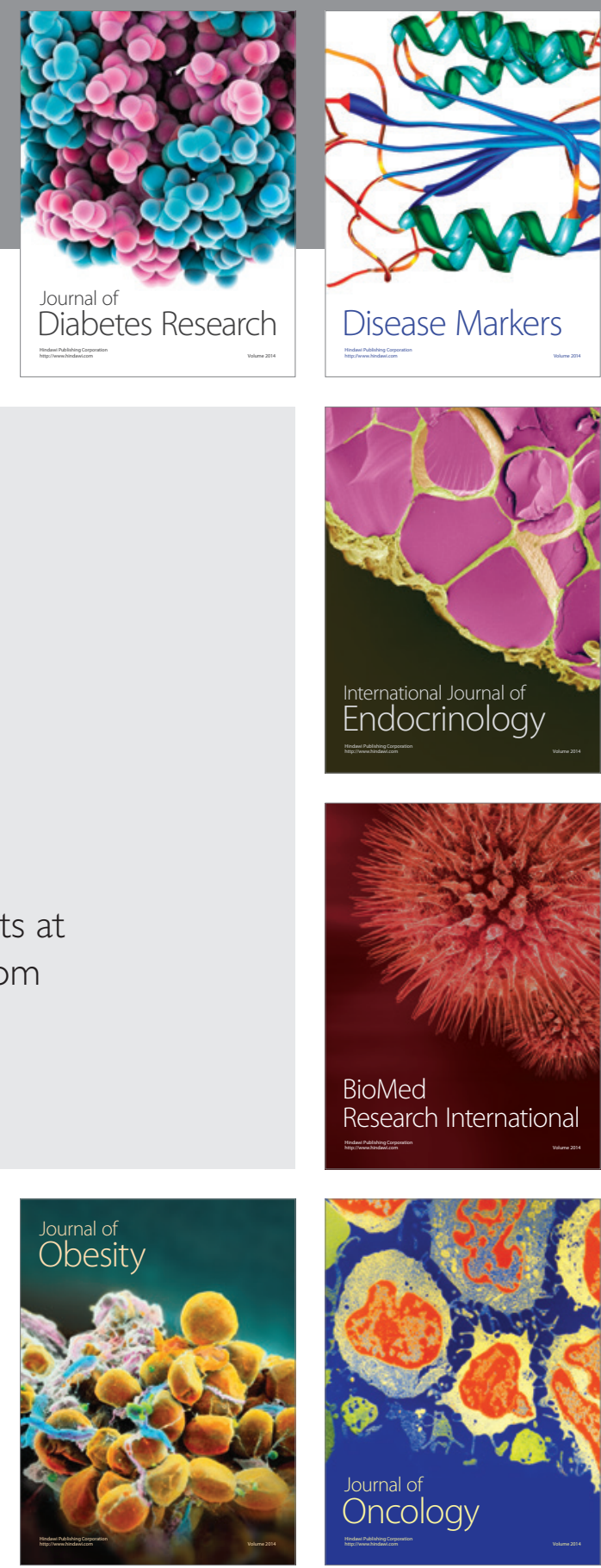

Disease Markers
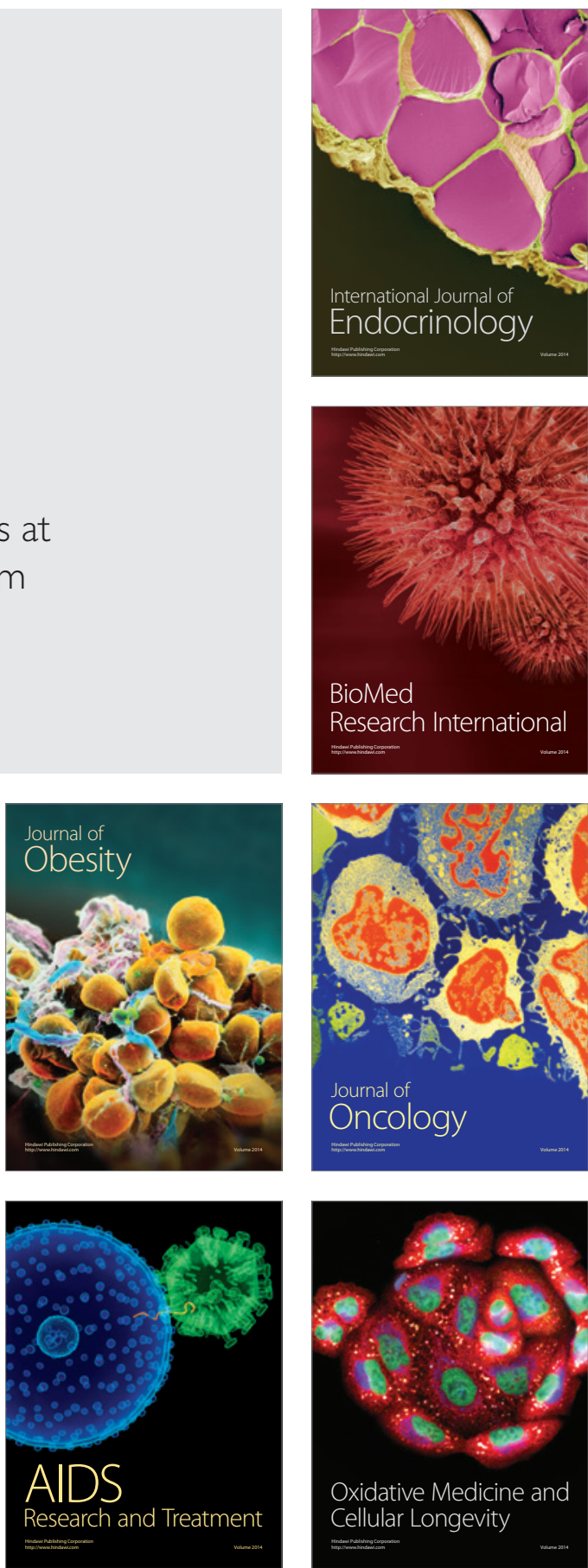